\section{dr. Monika \\ Govekar - \\ Okoliš \\ Filozofska \\ fakulteta $v$ \\ Ljubljani}

\title{
VZGIBI SPONTANEGA IZOBRAŽEVANIA
}

\section{Poročilo o anketiranju v Vipavskem Križu in Lokavcu ter predlogi prebivalcem}

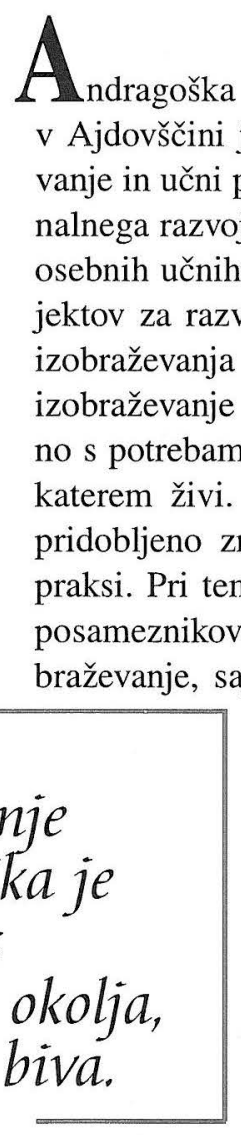

A v Ajdovščini je s temo Izobraževalno svetovanje in učni projekti odraslih - temelj regionalnega razvoja ugotavljala predvsem pomen osebnih učnih projektov in mreže učnih projektov za razvoj ljudi ter kraja, ki so temelj izobraževanja za regionalni razvoj. Danes je izobraževanje posameznika vse bolj povezano s potrebami kraja in širšimi cilji okolja, v katerem živi. Zato je najučinkovitejše tisto pridobljeno znanje, ki je takoj uporabno $\mathrm{v}$ praksi. Pri tem vse bolj prihajata v ospredje posameznikovo individualno učenje in izo-

Spontano

izobraževanje posameznika je

povezanos

potrebami okolja, $v$ katerem biva. ne moremo več pokriti samo $\mathrm{z}$ institucionalnim in skupinskim izobraževanjem. Andragoška poletna šola (APŠ) se je osredotočila predvsem na praktično-terensko delo, pri čemer sta dve skupini udeležencev APŠ izvajali anketiranje po vaseh (Vipavski Križ, Lokavec, Budanje in Slap) Občine Ajdovščina. Cilj anketiranja je bil ugotoviti pojave spontanega izobraževanja ljudi po vaseh, poiskati oblike in raziskati možnosti individualnega izobraževanja in tistih vzorcev učenja, v zvezi s katerimi dejansko ni izobraževalne ponudbe na vasi. Tako je bil namen anketiranja odkriti po vaseh vzgibe spontanega izobraževanja ljudi, v okviru tega pa ugotavljati možnosti za razvoj spontanih oblik učenja in izobraževanja, ki dejansko izhajajo iz potreb posameznikov, njihovih najbližjih in potreb okolja samega, kjer živijo.

\section{VIPAVSKI KRIŽ}

Skupina udeležencev APŠ (Matjaž Kološa, Jožica Krašovec, Andreja Pignar, Irena Božič, Petra Kodre, Jožef Kirbiš, Jasna Železnikar, Danica Kotnik in Monika Govekar Okoliš) je 6. 6. 2000 naključno anketirala prebivalce vasi Vipavski Križ. Večina iz skupine je bila prvič v Vipavskem Križu. Vas stoji na podolgovatem griču sredi Vipavske doline. Po prvih vtisih je Vipavski Križ zaprta (obdana z obzidjem), zelo stara vas. Kot so povedali domačini, stoji Vipavski Križ na temeljih prazgodovinskega gradišča in spada med zgodovinsko najzanimivejše kraje $v$ Vipavski dolini in je v celoti spomeniško zavarovan. Prvič je bil omenjen leta 1252 kot »villa Crucis«, največji razcvet pa je doživel v 16. stoletju. Vaščani so omenili, da je naselje dobilo tržne pravice že leta 1507, leta 1532 pa mestne pravice (pravica do lastnega sodnika in letnih sejmov). Zelo zanimiv je najstarejši del, imenovan $\mathrm{V}$ gasah, kjer so ozke uličice ' $z$ eno- ali dvonadstropnimi hišami. V vasi sta župnijska cerkev sv. Križa (poznogotska stavba, ki so jo kasneje barokizirali) in kapucinski samo- 
stan (od leta 1636), kjer je deloval znani baročni pisec Janez Svetokriški. V Vipavskem Križu imajo otroški vrtec in štiriletno osnovno šolo ter mladinski pevski zbor. Decembra 1999 so ustanovili tudi turistično društvo. V vasi so tri kmetije, nekateri pa se ukvarjajo $\mathrm{z}$ vinogradništvom (vinogradi so zunaj obzidja). Nimajo pa trgovine, ne gostilne ne bifeja.

Vaščani Vipavskega Križa so omenili, da danes prebiva v vasi 180 ljudi, od teh je šest oseb upokojenih, nekateri se ukvarjajo s kmetovanjem in vinogradništvom, drugi pa se večinoma vozijo na delo $\mathrm{v}$ Ajdovščino (Fructal, Lipa, Minotest, Primorje). Nekaj mladih študira v Ljubljani. Mladi se vračajo nazaj, tako da jih večina ostane $\mathrm{v}$ vasi. V letu 1999 so začeli obnavljati stari grad, ki naj bi služil kulturnim namenom. Delovati je začelo tudi turistično društvo. Ljudje se pri tem srečujejo in družijo, ne le vaščani (mladina ima svoja srečanja), tudi s prebivalci Ajdovščine, ki pripravljajo različne prireditve v vinski kleti starega gradu. Pri tem prihaja do izmenjave različnih izkušenj, znanja in do spontanega izobraževanja ter učenja oziroma pridobivanja novih spoznanj ter znanja po neformalni poti.

V zvezi z izobraževanjem je treba omeniti tudi medije (časopisi, knjige, reklamna sporočila, TV in radio), slikarske in kiparske kolonije samoukov in akademskih slikarjev ter obiske turistov.

Skupina APŠ je naključno anketirala vaščane različne starosti:

\section{Starost anketiranih}

20 do 30 let

30 do 50 let

$\mathrm{Nad} 50$ let

Skupaj

Niso želeli odgovarjati
Število oseb
Pri anketiranju smo glede na anketirane osebe in prve vtise dobili pričakovane rezultate. Ugotovili smo, da v Vipavskem Križa nimajo izobraževalne ponudbe in da vse oblike izobraževanja odraslih potekajo spontano, v skladu s potrebami posameznikov in potrebami kraja. Ljudje spoznavajo, da obstajajo področja, ki jih ne poznajo, da o nith ne vedo ničesar.

Vsebine spontanega učenja spoznamo po odgovorih vprašanih oseb o tem, kaj je tisto, česar ne vedo ali bi morali vedeti ali imajo željo, da bi vedeli. Večina ljudi meni, da v življenju sproti spoznavajo, česa ne znajo ali ne vedo. Na primer, upokojenec ne zna ravnati z elektriko, zato se obrača na sina. Ljudje so omenili, da jim primanjkuje znanja v zvezi s študijem in službo (zakoni, predpisi), mladi ugotavljajo, da imajo premalo računalniškega znanja, drugi ne vedo, kaj bi lahko počeli v prostem času, niso seznanjeni s splošno-izobraževalnimi dejavnostmi, ki potekajo v Ajdovščini. Tisti, ki se ukvarjajo s kmetovanjem, ne vedo, kje in kako pridobiti znanje o kmetovanju. Tisti, ki skrbijo za pred kratkim ustanovljeno turistično društvo, ne vedo, kako promovirati kraj s ponudbo turistične dejavnosti. Nekaterim primanjkuje znanja o trženju lastnih izdelkov.

Glede na omenjene vsebine potreb po znanjih so se pokazali tudi določeni vzorci spontanega izobraževanja ljudi v Vipavskem Križu. Potrebe vaščanov po znanjih so vezane na delo in življenje v vasi, zato skušajo vse, česar ne vedo, rešiti v krogu družine, sorodnikov, prijateljev, znancev, zlasti tistih, ki vedo, da lahko pomagajo, in ki imajo določena znanja.Vaščani si pomagajo tudi med seboj, nasvete iščejo pri vaškem duhovniku, s katerim dobro sodelujejo, obračajo se na sodelavce, odvisno od potreb po znanju, pogosto pa tudi na turistično društvo. Sicer je večina anketiranih omenjala, da pogosto obiščejo knjižnico LU v Ajdovščini, informacije in podatke iščejo torej $\mathrm{v}$ knjigah, časopisih, na TV, radiu (Robin in Nova), CD (kdor ima računalnik), 
po potrebi tudi pokličejo veterinarsko službo. Sicer pa se obračajo na formalnopravne ustanove v Ajdovščini (na primer na občino).

Ugotovili smo, da moški upokojenci večinoma ostajajo doma in opravljajo različna dela, povezana s hišo (zidanje, klesanje kamnitih oken in ograj) in vrtom (ali kmetijo in vino-

\section{Prebivalci Vipav- skega Križa si predvsem želijo obnoviti kraj.}

gradom). Ženske upokojenke opravljajo gospodinjska dela (kuhanje, pečenje peciva in drugih sladic), varujejo otro$\mathrm{ke}$, ena pa intenzivneje sodeluje tudi $\mathrm{v}$ turističnem društvu, seveda poleg gospodinjskih del. Drugi poleg rednega dela v službi opravljajo različna dela, na primer inženir elektronike se ukvarja z elektroniko, avtomehanik se trenutno izobražuje $\mathrm{v}$ programu ekonomsko-komercialni tehnik, obrtnik izdeluje polizdelke iz lesa, prodajalka, zaposlena v Ajdovščini, skrbi še za gospodinjstvo in varuje otroke, gimnazijski maturant je honorarno zaposlen pri zasebniku, kustos v Goriškem muzeju sodeluje v turističnem društvu in pri načrtovanju ter prenovi kraja (parkirišče, vinska grajska klet, razstavni prostor).

Anketa je pokazala, da je večina prebivalcev Vipavskega Križa osebno zadovoljna in $\mathrm{s}$ tem, kar delajo doma (načrtujejo in obnavljajo hiše, glede gradnje morajo upoštevati predpise spomeniškega varstva), drugi pričakujejo spremembe na poklicnem področju, da se jim bi uresničila želja (matere) po poklicnem napredovanju, ko bodo otroci odrasli, avtomehanik se je že odločil za napredovanje $v$ komercialnega tehnika, drugi bi se rad izobrazil na področju glasbe in kiparstva, tretji pridobil znanja s področja elektrotehnike. Nekateri bi se radi usmerili v dodatno izobraževanje, ker želijo imeti višjo stopnjo izobrazbe in zaradi zahtev delovnega mesta. Drugi bi se radi seznanili s slikanjem. po obnovi kraja, dokončanju krajevnih načrtov. Želijo si več podpore ter posluha občine in države za turistično društvo ter razvoj kraja, da bi v kraju čimprej obnovili grad in uredili trgovino ter bife. V kraju želijo čimprej urediti tudi promet in parkirišče.

\section{PREDLOGI PREBIVALCEM VIPAVSKEGA KRIŽA}

1. Pomembna je povezanost med občino Ajdovščina in Vipavskim Križem, ki lahko pripomore $\mathrm{k}$ nadaljnjemu razvoju turističnega društva. Pri tem naj bi bilo vključenih čim več vaščanov. Prihajalo naj bi do večjega spontanega izobraževanja in zadovoljevanja potreb po znanju, ki ga potrebujejo ljudje na vasi.

2. Turistično društvo bi bilo lahko središče, ki bi zbiralo informacije o dogajanju in načrtovanih dejavnostih na vasi ter $\mathrm{v}$ okoliških krajih, lahko bi skrbelo za informativno glasilo (lahko tudi za oglasno desko v središču vasi), ki bi ga ponudil tudi širšemu okolju.

3. Turistično društvo bi lahko oblikovalo poleg informacijskega središča tudi svetovalno središče, zato naj bi se imenovalo informacijsko-svetovalni center. Predlagamo, da bi se omenjeno središče povezalo z Občino Ajdovščina, Zavodom za kulturo, izobraževanje in šport v Ajdovščini, kjer bi bil sedež andragoške ustanove. Strokovnjaki - svetovalna služba iz Ajdovščine in svetovalec ali kulturni animator (predlagamo mag. Boruta Koloinija) - naj bi skupaj, po dogovoru in glede na potrebe prebivalcev vasi, dajali informacije, omogočili oblikovanje določenega izobraževalnega programa (študijski krožki, kako na primer popestriti turizem $v$ manjšem kraju, prodaja domačih izdelkov, kulturno-zabavne prireditve za vse generacije ...). $\mathrm{K}$ razvoju kraja in znanju ljudi 
bi veliko pripomoglo tudi organizirano individualno izobraževanje. Animator v vasi naj bi bil sposoben izobraževalnega svetovanja in kulturne animacije.

4. Večja povezanost in pretok informacij med vasjo in Ajdovščino (organizacija okroglih miz, kulturnih prireditev, študijskih krožkov, obveščanje z lepaki in zloženkami, Vipavski Križ naj bi imel informativno glasilo o prireditvah in posebnostih v vasi, ki naj bi seglo v širši slovenski prostor, na primer organiziranje kolonije mladih slikarjev, učencev OŠ ali SŠ - informacije bi razposlali po vseh šolah v Sloveniji, organiziranje srečanj za starejše - upokojence (študijski krožki) - vabila bi razposlali na univerze za tretje življenjsko obdobje in pritegnili seveda tudi domačine ...).

5. Uvedba devetletne osnovne šole.

6. Pridobitev trgovine in bifeja.

7. Odpreti bi morali manjšo pošto in postaviti bankomat (pomembno tudi za turiste), morda v okviru turističnega društva.

8. Obnovitev gradu, ki se arhitektonsko ujema s samostanom in vaško cerkvijo (lepa in zanimiva turistična točka). Zanimivi bi bili tudi kulturni poletni večeri na grajskem vrtu in različne izobraževalne dejavnosti ...

9. Ureditev prometa (parkirišče).

\section{LOKAVEC}

Skupina udeležencev APŠ (Jožica Krašovec, Matjaž Kološa, Tanja Jeras, Jasna Železnikar, Danica Kotnik, Petra Kodre, Irena Božič, Sabina Jelenc - Krašovec, Monika Govekar Okoliš) je 7. 6. 2000 obiskala Lokavec. To je razpotegnjena, velika vas $\mathrm{v}$ Vipavski dolini $\mathrm{z}$ več zaselki in približno 1200 prebivalci. Del skupine je obiskal spodnji, osrednji del Lokavca, drugi del pa bolj gričevnati predel Lokavca. Zaselki delujejo kot samostojne va-

si, ki se med seboj razlikujejo. Skupina, ki je obiskala nižinski del Lokavca, je ugotovila, da so v tem predelu bolj zastopane obrtne dejavnosti, kot so žaga, fužine, šiviljstvo, kovaštvo, zidarstvo, avtokleparstvo, pekarstvo, gostinstvo (dve gostilni). V drugem delu Lokavca pa se več ljudi ukvarja s kmetijstvom, sadjarstvom, vinogradništvom in živinorejo velike kmetije (do 150 glav živine). Veliko vaščanov je zaposlenih v Ajdovščini. Lokavec ima štirirazredno osnovno šolo za vse zaselke. Otroci se $\mathrm{v}$ šolo vozijo s šolskim avtobusom. Vrtec pa je v Ajdovščini.

Osnovna šola Lokavec je nekakšno kulturno središče. Z

Prebivalci Lokavcev skušajo oživiti tradicijo furmanstva.
Goriškim muzejem vsako leto prireja Lokavške kulturne dneve. Sodelujejo učenci lokavške osnovne šole, otroški pevski zbor, lokavški Aktiv kmečkih žena (od leta 1991). Potekajo tudi različne predstavitve novih knjig in razstave izdelkov osnovnošolcev. $\mathrm{V}$ okviru prireditve organizira Zveza prijateljev mladine ob mednarodnem dnevu družine pri lovski koči nad Lokavcem »srečanje družin« .

Lokavec ima tudi kovaški muzej, kjer je včasih delovala kovačija. Znani so bili po »furmanstvu«. Vaščani skušajo tradicijo furmanstva oživiti, saj so se nekoč z njim v tem kraju preživljali. Kraj ima zasebno pekarno, šiviljstvo, frizerski salon, avtokleparja, deluje pa tudi zasebna elektrarna. Pojavlja se tudi pobuda za obnovitev starega mlina, ki bi bil prav gotovo zanimiva turistična točka. Lokavec ima tri cerkve, kjer se ljudje najpogosteje zbirajo in srečujejo. V cerkvah organizirajo koncerte, imajo svoj cerkveni zbor in šolo za starše. Drugih oblik neformalnega izobraževanja (študijskih krožkov) ni. Izobraževalni vplivi prihajajo v Lokavec tudi prek medijev (časopisi, revije, knjige, TV in radio). Po navedbah krajanov je večina aktivnega prebivalstva zaposlena. 


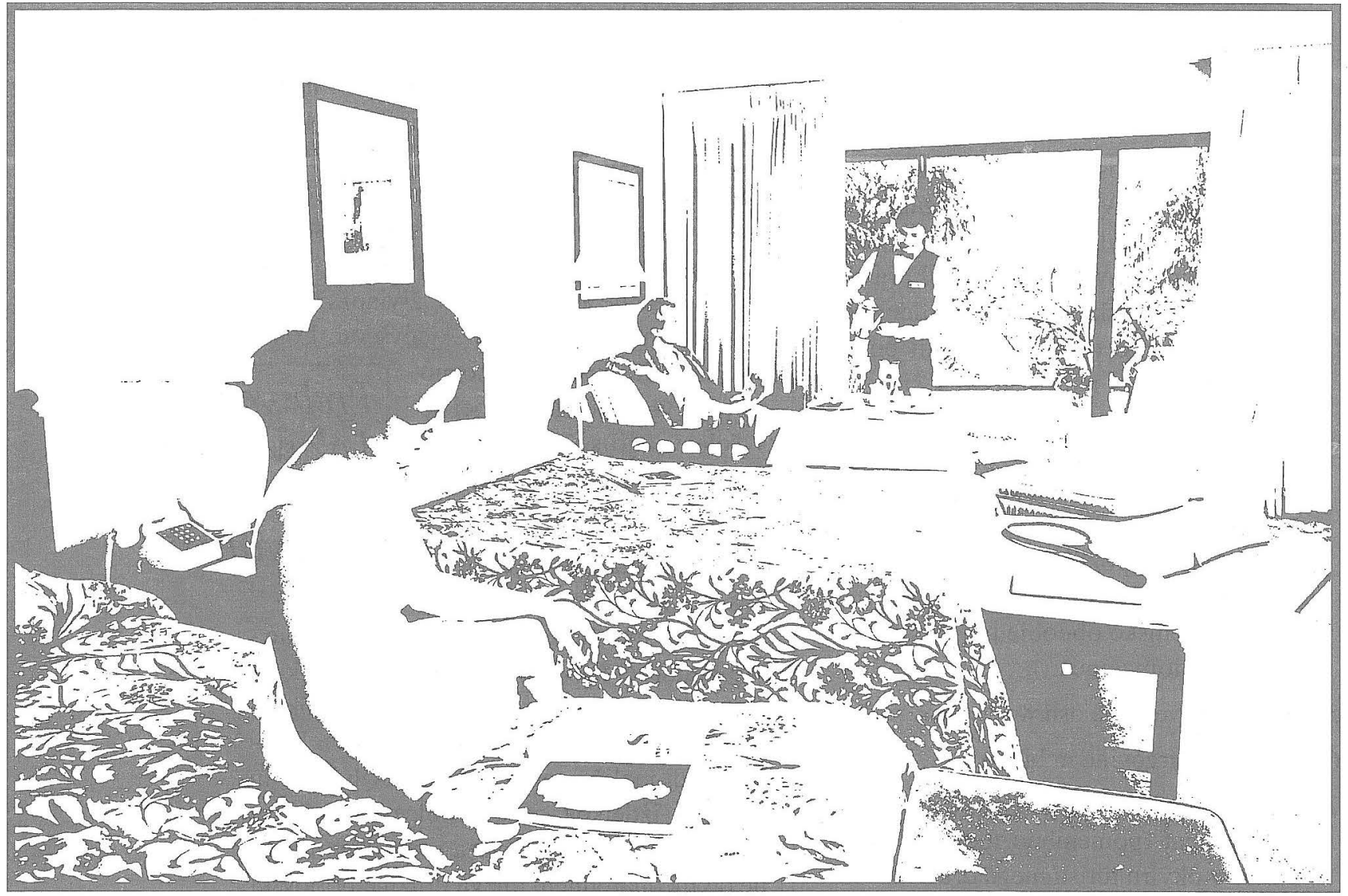

Skupina APŠ je naključno anketirala prebivalce različne starosti:

\section{Starost anketiranih}

Mlajši od 30 let Število oseb

30 do 50 let 4

$\mathrm{Nad} 50$ let 11

Skupaj

Rezultati ankete so pokazali, da Lokavec, podobno kot Vipavski Križ, nima izobraževalne ponudbe za odrasle ljudi. Izobraževanje poteka spontano, glede na njihove osebne potrebe in glede na potrebe kraja. Redno se srečujejo ob kulturnih prireditvah ali po maši. Tovrstna srečanja so edina oblika, ki v kraju spodbuja spontano učenje in izobraževanje ljudi, saj so v celoti vezani na Ajdovščino. Kako poteka spontano učenje, smo ugotavljali iz anketnih odgovorov ljudi, ki so nam priznali, da marsičesa ne vedo, sicer pa je vse odvisno od okoliščin in potreb po znanju. Nekdo nam je zatrdil, da je sam svoj mojster in da mu nihče ne more pomagati, saj opravlja specifično (unikatno obrtno) delo. Drugi bi se rad naučil, kako škropiti drevje proti škodljivcem, vendar ne ve, kako priti do podrobnejšega znanja o škropljenju. Nekateri so omenili, da jim primanjkuje znanja iz gradbeništva, o novih materialih in da bi se radi naučili novosti. Pokazale so se potrebe po znanju iz čebelarstva, sadjarstva in gojenja drobnice. Nekdo bi se rad naučil čebelariti, vendar ne ve, na koga se lahko obrne. Ljudje potrebujejo znanje o vzgoji otrok, saj se sprašujejo, kako pravilno vzgajati otroke, ne vedo, kaj je treba narediti in kako poskrbeti za starejše ljudi, kako bi 
lahko sami skrbeli zase v starosti in kako si lahko pomagajo. Nekateri bi se radi naučili bolje prodajati svoje izdelke, da bi bolje zaslužili, tretji bi radi vedeli, kako ravnati v neznanem kraju in kako se znajti.

Kmetovalci so povezani s kmetijsko zadrugo, pomagajo pa si tudi med seboj. Obračajo se na ràzlične ustanove (kmetijsko svetovalno službo, żdravstveni dom, šolo in LU v Ajdovščini). Novega in potrebnega specifičnega znanja pa ne iščejo le pri strokovnjakih in ljudeh, ki kaj vedo, temveč se tudi individualno izobražujejo. Obiskujejo knjižnico, berejo knjige, revije, časopise, poslušajo radio in gledajo TV, sicer pa se tudi dodatno izobražujejo na LU v Ajdovščini. Uradne zadeve rešujejo na Občini Ajdovščina.

Glede dejavnosti anketiranih lahko povzamemo, da se večina ljudi, ki so zaposleni (avtoklepar, mesar, kovač, avtoprevoznik, veterinarski tehnik), ukvarja še s kmetijstvom, živinorejo (ovčjerejo), vinogradništvom, sadjarstvom in vrtnarstvom. Manj se jih ukvarja $z$ zidanjem, ena oseba se ukvarja $\mathrm{z}$ modeliranjem, druga s fotografiranjem. Upokojenci so doma in delajo na svoji domačiji, večinoma se ukvarjajo s kmetovanjem, vrtnarjenjem, sadjarstvom in vinogradništvom. Ena oseba zbira nabožne predmete in starine. Nekaj mladih pa študira v Ljubljani.

Ugotavljamo, da so potrebe po znanju ljudi povezane $z$ njihovim delom in življenjem ter potrebami, ki jih narekuje razvoj kraja. Vzorci spontanega izobraževanja so razvidni iz tega, kako in kje ljudje iščejo znanje ter na koga se obračajo za nasvet ali določeno znanje. Večina anketiranih je odgovorila, da se $v$ tem primeru obrne na osebo, ki pozna problematiko (domače, sorodniki, sosedje, prijatelji, sodelavci). Velikokrat iščejo nasvete pri starejših ljudeh, ki imajo izkušnje.
Anketa je pokazala, da so ljudje na splošno zadovoljni s seboj in s tem, kar delajo, nekateri pa si želijo pridobiti še dodatno znanje. Nekdo si želi opraviti vozniški izpit, drugi pridobiti znanje $\mathrm{v}$ zvezi s fotografiranjem, rad bi imel svojo fotografsko delavnico, tretji znanje o trženju, saj bi tako laže prodajal svoje domače izdelke. Nekdo si želi postati čebelar, vendar ne ve, na koga naj se obrne, drugi bi se rad naučil zidarjenja, tretji bi se rad ukvarjal $\mathrm{z}$ »oldtimerji

Med anketiranimi je bilo tudi nekaj želja glede razvoja kraja samega, in sicer, da bi dobili v Lokavcu športno igrišče, da bi uredili pločnike do Ajdovščine, na splošno pa želijo boljšo obveščenost v skupnosti.

Prebivalci Lokavca živijo v razpotegnjeni vasi, na robu Vipavske doline, in so med seboj premalo povezani, $\mathrm{k}$ temu morda pripomore že sama geografska lega. Lokavec nima posebej organiziranega izobraževanja odraslih, kajti vse formalne oblike izobraževanja potekajo v Ajdovščini. Formalno središče sta osnovna šola in cerkev, druge oblike neformalnega izobraževanja pa potekajo spontano in sproti, odvisno od potreb (posameznikov ali skupnosti). Zato je najpogostejši način medsebojne pomoči, reševanja problemov ali pridobivanja novega znanja vezan na izkušnje, poznanstva in zaupanje med ljudmi.

\section{PREDLOGI PREBIVALCEM LOKAVCA}

1. Lokavec mora dobiti kontaktno osebo (animatorja), ki bo povezovala vaščane, skrbela za informiranje, izobraževanje in pomoč. Predlagamo, da se na primer oseba iz svetovalne službe (ali kdo drug) na osnovni šoli poveže s svetovalno službo na andragoškem centru, ki bi imel sedež v Ajdovščini (LU). Skupaj bi spremljala no- 


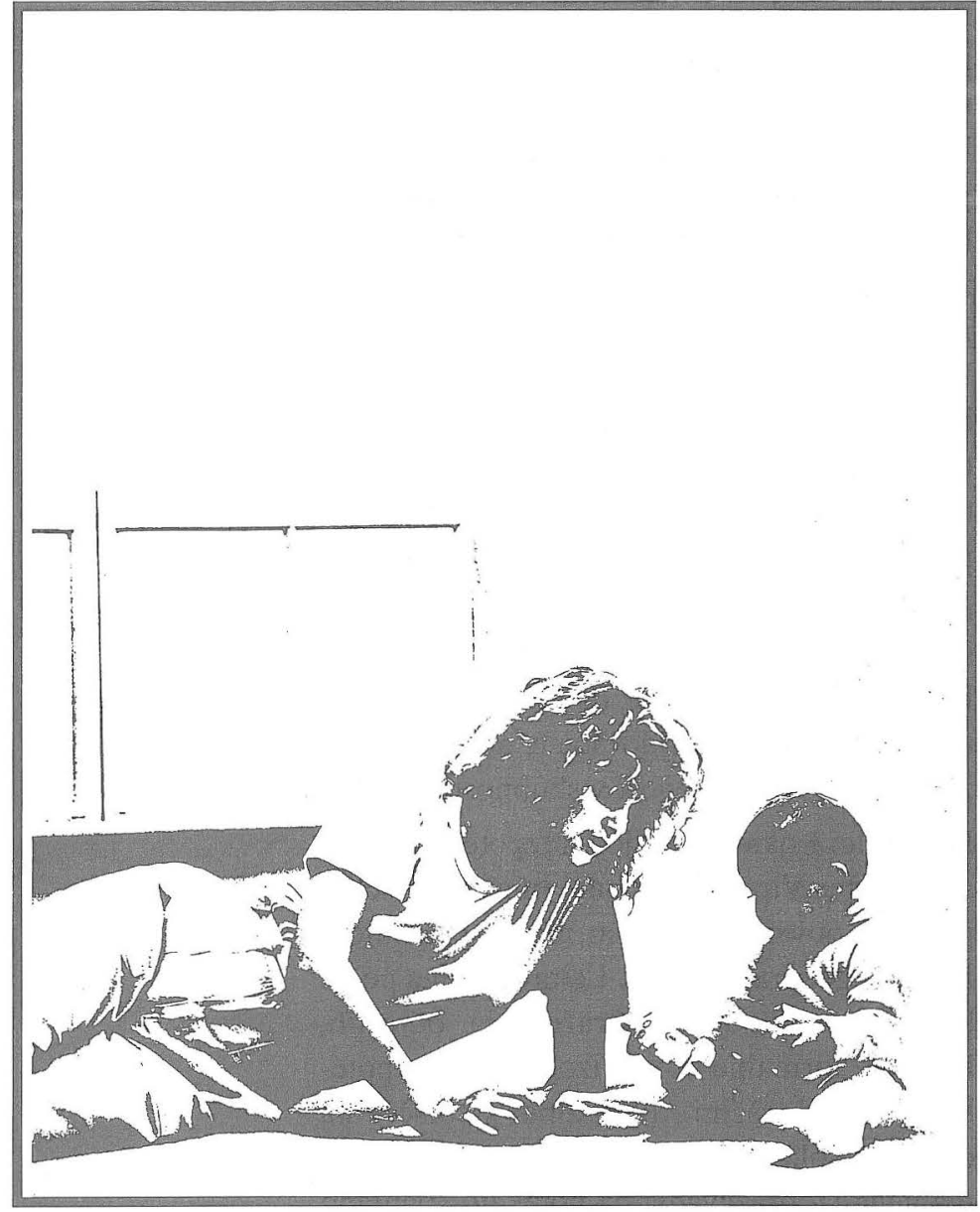

vosti, oblikovala individualne programe, odvisno od potreb po znanju. Prav tako bi moralo biti naselje bolj povezano z Občino Ajdovščina (občinsko informacijsko glasilo).

2. Osnovna šola $v$ Lokavcu bi morala postati devetletna. Ker so že doslej na osnovni šoli organizirali različne kulturne prireditve, naj bi se šola $v$ prihodnosti razvila $v$ izobraževalno-svetovalno središče, ne le za otroke in starše ter za kulturne prireditve, temveč tudi za druge odrasle. Osnovna šola bi se morala imenovati »učeča se šola«. To pomeni navzven odprto šolo, središče za kulturne, socialne, izobraževalne in športne dejavnosti. Tu naj bi potekalo izobraževanje otrok, različni krožki za mla- de, študijski krožki za odrasle in starejše. Vsekakor je to cenejša možnost kot gradnja kulturno-informacijskega svetovalnega središča, dopolniti je treba dosedanjo dejavnost šole in razširiti njeno delovanje na širše okolje. Informacijsko-svetovalna služba na osnovni šoli naj bi izdajala informacijsko glasilo, s katerim bi seznanjala ljudi o dogajanju in prireditvah (tudi izobraževalnih dejavnostih) v vasi, saj je informiranost slaba.

3. Ker osnovna šola $v$ Lokavcu sodeluje $z$ Goriškim muzejem, se nam postavlja vprašanje, zakaj se LU Ajdovščina bolj ne poveže in sodeluje s šolo ter ponudi možnosti za skupinsko učenje (študijski krožki, tečaji, druge dejavnosti). Potrebe po znanju se pojavljajo na strokovnih področjih (čebelarstvo, sadjarstvo, gojenje drobnice, fotografija, trženje izdelkov). Prav tako bi lahko pripravili vrsto individualnih izobraževalnih programov. Tako bi ljudje lahko opravljali različna dela, ki jih veselijo in zanimajo. Hkrati pa bi lahko tovrstne dejavnosti tudi pripomogle $\mathrm{k}$ razvoju kraja, $\mathrm{k}$ razvoju krajevnega turizma pa bi lahko pripomogla prodaja domačih izdelkov in pridelkov kot lokavških posebnosti.

4. Predlagamo ustanovitev vrtca, morda v okviru šole ali zraven nje.

5. Lokavec potrebuje tudi športno-rekreativno središče ali vsaj športno igrišče za igre $\mathrm{z}$ žogo in atletiko.

6. Urediti je treba tudi infrastrukturo (ceste, pločniki, razsvetljava).

7. Stare stavbe, ki so se ohranile, na primer stari mlin, bi lahko postale lokavška turistična zanimivost, vendar bi jih morali najprej (s pomočjo Občine Ajdovščina) obnoviti. Seveda bi morali še naprej skrbeti za kovaški muzej. Obrtniki bi lahko imeli svoj sejem, na katerem bi prodajali svoje izdelke, prav tako kmetovalci. Reklamna sporočila, za katera bi moral skr- 
beti animator, pa bi morali razpošiljati po Sloveniji, na primer na slovensko obalo, saj bi lahko tako marsikaterega turista privabili na ogled tudi $\mathrm{v}$ ne tako oddaljeni Lokavec. Turistična ponudba bi lahko vključevala obisk starega mlina, obisk pri osebi, ki zbira starine (ta bi lahko imela urejeno muzejsko sobo), ogled kovaškega muzeja in prireditve $\mathrm{v}$ zvezi $\mathrm{s}$ furmanstvom, ogled zasebne elektrarne, cerkva in njihovih znamenitosti ter kulturne dejavnosti idr.

8. V Lokavcu bi morali spodbujati tudi razvoj kmečkega turizma.

\section{SKLEPNE MISLI}

V obeh primerih, v Vipavskem Križu in Lokavcu, se je pokazalo, da se morata Občina Ajdovščina in Zavod za kulturo izobraževanje in šport bolj povezovati s krajani. Kako? Predlagamo, da bi andragoška ustanova - LU Ajdovščina s svetovalci pomagala pri spontanem izobraževanju in učenju ljudi. Ljudje so doslej sami iskali vire za pridobivanje znanja v svojem neposrednem okolju (doma, pri sorodnikih, prijateljih, znancih, sovaščanih, pri tistih, ki več vedo in ki jim zaupajo). Tako je pomembno, da v vsakem naselju določijo posameznika, sociokulturnega animatorja, ki bi skrbel za pretok informacij od občine in andragoške ustanove - LU do prebivalcev, v skladu $\mathrm{z}$ njihovimi potrebami po znanju in

Ljudje potrebujejo znanje $v$ čim krajšem času, zato je pomembno, da so jim na voljo tudi andragoške ustanove s svojimi izobraževalnimi-svetovalnimi službami, ki bi jim pomagale najti najkrajšo in učinkovito pot do znanja. Pri tem bi morala občina in država zagotoviti posameznikom tudi finančno podporo za razvijanje različnih individualnih projektov, ki bi jih lahko uspešno vključili v razvoj kraja. osebnem razvoju ter potrebami po razvoju kraja. Tako bi najhitreje prišlo do izmenjave potreb ustanov in ljudi in s tem do oblikovanja načrtov za razvoj posameznikov in razvoj kraja. V ta namen bi bilo treba poskrbeti tudi za posebne informativne tiskane vire (informativna krajevna glasila), sicer pa ljudje poslušajo lokalni radio (Robin in Nova), gledajo TV in berejo knjige, časopise, revije, reklamna sporočila ... Na splošno ugotavljamo, da so vzorci in strategije spontanega učenja in izobraževanja prebivalcev Vipavskega Križa in Lokavca podobni, čeprav se naselji razlikujeta po velikosti in številu prebivalcev ter po stopnji razvitosti (Vipavski Križ na primer nima trgovine, bifeja, pošte, bankomata). Ugotovitve omenjenih naključnih anketiranj so pokazale, da gre $\mathrm{v}$ obeh primerih za pomanjkljivo izobraževalno ponudbo. 